\title{
Study of Novel Selective mGlu2 Agonist in the Temporo-Ammonic Input to CA1 Neurons Reveals Reduced mGlu2 Receptor Expression in a Wistar Substrain with an Anxiety-Like Phenotype
}

\author{
Laura Ceolin, ${ }^{1}$ Sriharsha Kantamneni, ${ }^{1}$ Gareth R. I. Barker, ${ }^{1}$ Lydia Hanna, ${ }^{1}$ Laura Murray, ${ }^{1}$ E. Clea Warburton, ${ }^{1}$ \\ Emma S. J. Robinson, ${ }^{1}$ James A. Monn, ${ }^{2}$ Stephen M. Fitzjohn, ${ }^{1}$ Graham L. Collingridge, ${ }^{1,3}$ Zuner A. Bortolotto, ${ }^{1}$ \\ and David Lodge ${ }^{1}$ \\ ${ }^{1}$ Medical Research Council Centre for Synaptic Plasticity, University of Bristol, Bristol, BS8 1TD, United Kingdom, ${ }^{2}$ Neuroscience Research Division, Eli \\ Lilly and Company, Indianapolis, Indiana 46285, and ${ }^{3}$ Department of Brain and Cognitive Sciences, College of Natural Sciences, Seoul National University, \\ Gwanak-gu, Seoul, Korea 151-747
}

\begin{abstract}
Group II metabotropic receptors (mGluRs) regulate central synaptic transmission by modulating neurotransmitter release. However, the lack of pharmacological tools differentiating between mGlu2 and mGlu3 receptors has hampered identification of the roles of these two receptor subtypes. We have used LY395756 [(1SR,2SR,4RS,5RS,6SR)-2-amino-4-methylbicyclo[3.1.0]-hexane2,6-dicarboxylic], an agonist at mGlu2 receptors and an antagonist at mGlu3 receptors in cell lines, to investigate the roles of these receptors in the temporo-ammonic path from entorhinal cortex to CA1-stratum lacunosum moleculare in rat hippocampal slices. Surprisingly, the degree of inhibition of the field EPSP induced by LY395756 fell into two distinct groups, with $\mathrm{EC}_{50}$ values of $<1 \mu \mathrm{m}$ and $>100 \mu \mathrm{m}$. In "sensitive" slices, LY395756 had additive actions with a mixed mGlu2/mGlu3 agonist, DCG-IV [(2S,2' $\left.R, 3^{\prime} R\right)-2-\left(2^{\prime}, 3^{\prime}\right.$-dicarboxycyclopropyl)glycine], whereas in "insensitive" slices, LY395756 reduced the effect of DCG-IV, with an $\mathrm{IC}_{50}$ of $\sim 1 \mu \mathrm{m}$. This separation into sensitive and insensitive slices could be explained by LY395756 acting as an mGlu2 agonist and mGlu3 antagonist, respectively, a finding supported by data from mice lacking these receptors. The heterogeneity was correlated with differences in expression levels of mGlu2 receptors within our Wistar colony and other Wistar substrains. The initial search for a behavioral correlate indicated that rats lacking mGlu2 receptors showed anxiety-like behavior in open-field and elevated plus maze assays. These findings have implications for rat models of psychiatric disease and are especially pertinent given that mGlu2 receptors are targets for compounds under development for anxiety.
\end{abstract}

\section{Introduction}

G-protein-coupled metabotropic glutamate receptors (mGluRs) are considered good targets for psychiatric and neurological diseases (Niswender and Conn, 2010). In particular, agonists at group II mGluRs (mGlu2 and mGlu3) have recently attracted considerable attention because of positive clinical trials in anxiety and schizophrenia (Grillon et al., 2003; Patil et al., 2007; Dunayevich et al., 2008). In the brain, they are mainly located presynaptically (Petralia et al., 1996; Shigemoto et al., 1997) and inhibit glutamate release (Cartmell and Schoepp, 2000). Identifying the roles of the two constituent group II receptors, however, has been thwarted by lack of pharma-

\section{Received Jan. 25, 2011; accepted March 7, 2011.}

This work was supported by the Medical Research Council and the Centre for Cognitive Neuroscience (Eli Lilly). L.C. and L.H. were supported by scholarships from the University of Bristol and Biotechnology and Biological Sciences Research Council (BBSRC), respectively. S.K. was supported by a BBSRC grant (to J. M. Henley). We thank members of Lilly Centre for Cognitive Neuroscience and Silvia Gatti of Hoffman-La Roche for helpful discussions.

Correspondence should be addressed to David Lodge, Medical Research Council Centre for Synaptic Plasticity, School of Physiology and Pharmacology, University of Bristol, Bristol, BS8 1TD, UK. E-mail: David.Lodge@bristol.ac.uk.

S. M. Fitzjohn's present address Eli Lilly \& Co., Erl Wood Manor, Windlesham, GU20 6PH, UK.

DOI:10.1523/JNEUROSCI.0418-11.2011

Copyright $\odot 2011$ the authors $\quad 0270-6474 / 11 / 316721-11 \$ 15.00 / 0$ cological agents. Several agonists, including DCG-IV $\left[\left(2 S, 2^{\prime} R, 3^{\prime}\right.\right.$ $R)-2-\left(2^{\prime}, 3^{\prime}\right.$-dicarboxycyclopropyl)glycine ] and LY354740 [(1S,2S,5R,6S)-(+)-2-aminobicyclo[3.1.0]hexane-2,6-dicarboxylic acid], activate mGlu2 and mGlu3 receptors equi-effectively at submicromolar concentrations, with essentially no activity at other glutamate receptors (Hayashi et al., 1993; Monn et al., 1997; Schoepp et al., 1999). Activation of both mGlu2 and mGlu3 receptors can be competitively and selectively antagonized by submicromolar concentrations of LY341495 [(2S,1'S,2'S)-2-(9-xanthylmethyl)-2-(2'carboxycyclopropylglycine] (Kingston et al., 1998).

Subtype selective agents are, however, needed. It is therefore of interest that, among a series of compounds related to LY354740, one (compound 13) showed submicromolar agonist activity at human recombinant mGlu2 receptors expressed in non-neuronal cells with antagonist activity at human recombinant mGlu3 receptors (Dominguez et al., 2005). This compound, LY395756 [(1SR,2SR,4RS,5RS,6SR)-2-amino-4methylbicyclo[3.1.0]-hexane2,6-dicarboxylic acid] is therefore the first reported selective mGlu2 agonist and hence a potentially useful agent for discriminating between the roles of mGlu2 and mGlu3 receptors. 
To confirm the pharmacology of this compound in a native neuronal system and to initiate a series of studies discriminating the roles of mGlu2 and mGlu3 receptors, the stratum lacunosum moleculare of CA1 (CA1-SLM) in the hippocampus of Wistar rats was selected for study. Pyramidal cells in CA1 receive a direct input from layer III of the entorhinal cortex, known as the temporo-ammonic pathway (TAP), which synapses in the SLM (Steward and Scoville, 1976; Witter and Amaral, 2004). Here the density of group II mGluR expression is high (Petralia et al., 1996; Shigemoto et al., 1997) and considerably reduced by entorhinal cortex lesions (Shigemoto et al., 1997). Previous electropharmacological studies in the rat TAP have demonstrated an important presynaptic regulation by group II mGluRs (Kew et al., 2001; Capogna, 2004; Price et al., 2005; Giocomo and Hasselmo, 2006), and knock-out (KO) studies in mice have indicated that both mGlu2 and mGlu3 receptors have important modulatory roles in this and other hippocampal pathways (Tamaru et al., 2001; Kew et al., 2002).

Here we report heterogeneity in the regulation of synaptic transmission in the TAP by group II mGluRs. In many preparations, the effects were attributed to mGlu2 receptors but, surprisingly, in others to mGlu3 receptors. This variability is explained by different levels of mGlu2 receptor expression, which varies between Wistar rat substrains and coincides with anxiety-like behaviors. The potential value of these Wistar substrains for studying the role of individual group II mGluRs in animal models of brain diseases is discussed.

Parts of this work have been published previously in abstract form (Ceolin et al., 2008).

\section{Materials and Methods}

\section{Slice preparation}

Rats. Most experiments were performed using hippocampal slices prepared from male Wistar rats, aged 2 weeks and purchased from the University of Bristol Animal Facility. Animals were housed in a regulated environment $\left(21 \pm 1^{\circ} \mathrm{C}\right)$ with food available ad libitum and maintained on a $12 \mathrm{~h} \mathrm{light/dark} \mathrm{cycle.} \mathrm{Animals} \mathrm{for} \mathrm{some} \mathrm{experiments} \mathrm{were} \mathrm{purchased}$ directly from B\&K Universal Ltd. UK, Charles River UK, and Harlan Laboratories UK. All experiments were performed in the light phase and in accordance with the Animals (Scientific Procedures) Act 1986.

Animals were killed by cervical dislocation, and the brain was removed rapidly into oxygenated ice-cold artificial CSF (aCSF) (see below). Parasagittal hippocampal slices, $400 \mu \mathrm{m}$, were prepared in situ by slicing the entire cerebral hemisphere parallel to the midline using a Vibroslicer (Campden Instruments Ltd.) in aCSF composed of the following (in mM): $124 \mathrm{NaCl}, 26 \mathrm{NaHCO}_{3}, 3 \mathrm{KCl}, 1.4 \mathrm{NaH}_{2} \mathrm{PO}_{4}, 1 \mathrm{MgSO}_{4}, 2 \mathrm{CaCl}_{2}$, and 10 D-glucose (saturated with $95 \% \mathrm{O}_{2}$ and $5 \% \mathrm{CO}_{2}$ ). Slices were placed in a Petri dish containing bubbled aCSF in which the hippocampus was isolated from the remainder of the brain and left to recover at room temperature in aCSF for at least $1 \mathrm{~h}$. Slices were then transferred to the interface recording chamber, in which they were maintained at $29-30^{\circ} \mathrm{C}$ and perfused at $2 \mathrm{ml} / \mathrm{min}$ with oxygenated aCSF as above.

For some experiments, a "modified" preparation was used; thus, the CA3 region and part of the dentate gyrus were removed and a cut was made across stratum oriens and stratum radiatum between CA1 and the subiculum to reduce the risk of polysynaptic excitation of CA1 and of contamination from Schaffer collaterals (SC) (Colbert and Levy, 1992; Empson and Heinemann, 1995).

Mice. Wild-type (WT) adult mice (12-15 weeks) and separate mGlu2 and mGlu3 receptor knock-out mice were generated by homologous recombination (Linden et al., 2005) at Eli Lilly \& Co.. Slice preparation was essentially identical to that described in the previous section for rats for the modified slices.

\section{Stimulating and recording techniques}

The bipolar stimulation electrode, made from twisted insulated nickelchromium wire $(0.050 \mathrm{~mm}$ diameter $)$ and insulated except for the tip, was placed in the SLM of the subicular region. Occasionally, two stimulating electrodes were used, with the second positioned in either another part of the SLM or stratum radiatum. Single stimuli (or occasionally a pair with a $50 \mathrm{~ms}$ interval), comprising a square-wave pulse, $20 \mu \mathrm{s}$ in duration and $10-25 \mathrm{~V}$ in amplitude, were delivered at $30 \mathrm{~s}$ intervals $(0.033 \mathrm{~Hz})$.

The glass extracellular recording electrode, filled with $3 \mathrm{~m} \mathrm{NaCl}$ and with a resistance usually of 2-4 M $\Omega$, was generally placed in CA1-SLM and occasionally in stratum pyramidale. Positions of the recording and stimulating electrodes were adjusted so as to give optimal field EPSPs (fEPSPs). Input-output curves were obtained, and, to obtain baselines, the stimulus strength was adjusted so as to generate fEPSPs of $70-80 \%$ of the maximal response.

\section{Data acquisition and analysis}

The raw direct current signal was bandpass filtered at $0.1-3 \mathrm{kHz}$, digitized, and collected for online analysis at a sampling rate of $20 \mathrm{kHz}$ using WinLTP software (Anderson and Collingridge, 2007). The fEPSPs were signal averaged every $2 \mathrm{~min}$, and the slope between 25 and $75 \%$ of maximum was measured and plotted online. Data from single experiments were displayed as the slope of the signal averaged, postfiltered fEPSPs. For the pooling of experiments, the fEPSP slope was normalized to a $30 \mathrm{~min}$ baseline and expressed as the mean \pm SEM. Statistical significance was tested using paired or unpaired Student's $t$ test or one-way ANOVA, followed by Bonferroni's post hoc test as appropriate; $p$ values $<0.05$ were considered significant and are indicated in some figures by ${ }^{* *}$.

The concentration-response curves were plotted using GraphPad Prism program (GraphPad Software). Mean data were fitted with the logistic four-parameter equation.

\section{Compounds}

DCG-IV was obtained from Tocris Cookson. LY341495, LY379268 [ $1 R, 4 R, 5 S, 6 R$-2-oxa-4-aminobicyclo[3.1.0] hexane-4,6-dicarboxylate], and LY395756 were synthesized as reported previously (Dominguez et al., 2005).

Routinely compounds were dissolved in distilled water or equimolar $\mathrm{NaOH}$ at a concentration 1000 times greater than required; aliquots were frozen ready for subsequent use.

\section{Immunoblotting}

Primary antibodies used were anti-mGluR2 antibody (Millipore), antimGluR3 antibody (Alomone Labs), and anti- $\beta$-actin (Sigma-Aldrich). Horseradish peroxidase-conjugated secondary antibodies used were goat anti-rabbit IgG (Sigma) and goat anti-mouse IgG (Sigma). Proteins were separated on $8 \%$ polyacrylamide gel, blotted onto Immobilon-P membrane (Millipore), and probed with appropriate primary antibodies after blocking. For detection of the signal, the membranes were incubated with horseradish peroxidase-conjugated secondary antibodies (1:10,000 dilution; Sigma) for $60 \mathrm{~min}$, followed by substrate incubation with BM Chemiluminescence Blotting Substrate (Roche) or WestFemto substrate (Pierce). The chemiluminescence signal was detected on the Hyperfilm HP (GE Healthcare).

\section{Behavioral assays}

Preparation. Rats from two substrains [Wistar rats purchased from B\&K Universal Ltd. (B\&K:Wi) and Wistar rats purchased from Charles River (Crl:Wi)] were purchased as above or bred and reared in-house under identical conditions. They were group housed in cages randomly sited in the racks and, at 6 weeks old, were switched to a $12 \mathrm{~h}$ light/dark cycle (light phase, 8:00 P.M. to 8:00 A.M.). All behavioral tests were conducted on rats between the ages of 9-11 weeks. Observations were made between 9:00 A.M. and 4:00 P.M. in a test room that was uniformly and indirectly lit. Before the start of behavioral testing, animals were transported in their home cage and habituated to the test room for $15 \mathrm{~min}$.

Open-field test. The open field consisted of an indirectly lit wooden open-top arena $(90 \times 90 \mathrm{~cm})$. The walls inside the arena were surrounded with a black cloth to a height of $1.5 \mathrm{~m}$ to conceal the experimenter, and the floor of the arena was covered with sawdust, which was cleaned between rats. An overhead video camera was used to record the animal's behavior. Each rat was placed against the near wall of the open 
A
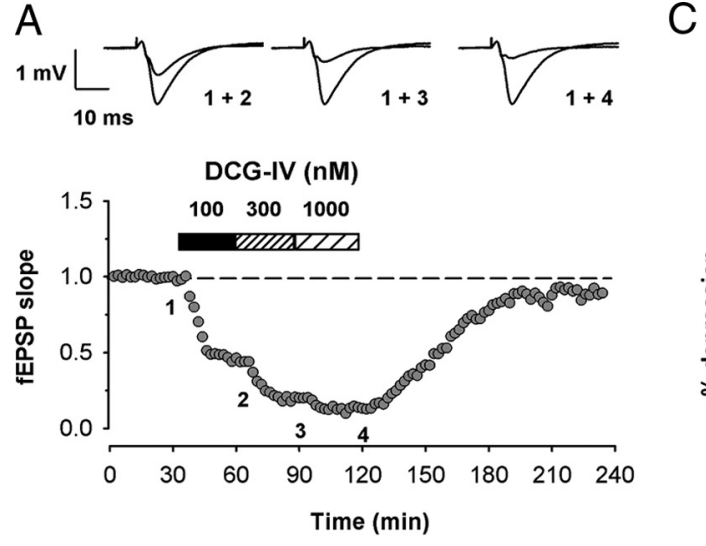

B

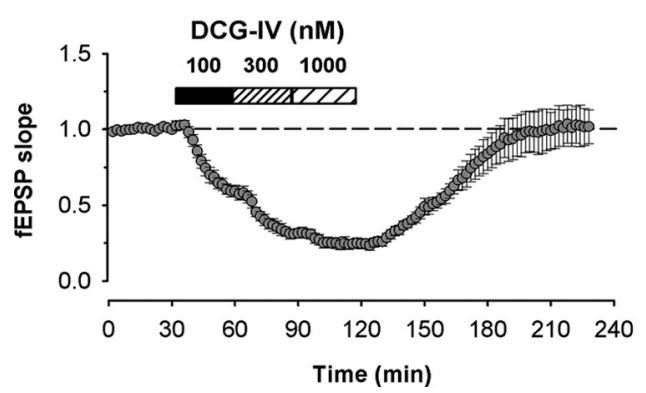

C

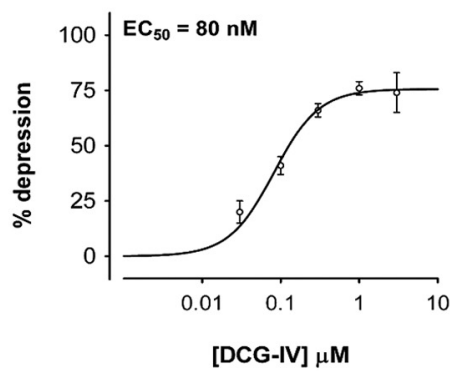

D
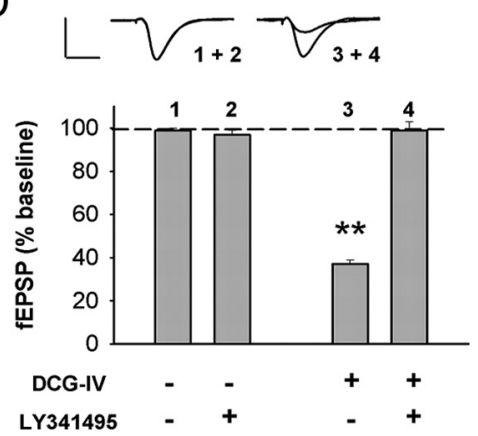

Figure 1. Activation of group II mGluRs by DCG-IV causes a concentration-dependent inhibition of synaptic transmission in the TAP-SLM pathway. $\boldsymbol{A}, \mathrm{A}$ representative single experiment showing the depression of the slope of the fEPSP in CA1-SLM after stimulation of the TAP by sequentially increasing concentrations of DCG-IV. The inhibition was reversed during washout. In this and subsequent figures, the application of drug and the concentration used are indicated by the bars and information above the plot. Each data point represents the average of four consecutive fEPSPs. Example traces, above, have been taken at the time points indicated. $\boldsymbol{B}$, Pooled data (mean \pm SEM) from six experiments as in $\boldsymbol{A}$. C, Concentration-response curve for the effect of DCG-IV on fEPSP slope. Each data point is the mean \pm SEM of 4-10 experiments. The curve has been plotted using a logistic four-parameter equation giving an $\mathrm{EC}_{50}$ value of $80 \mathrm{~nm}$. Statistically significant differences for individual concentrations of DCG-IV are given in Results. D, Histogram showing the lack of effect of LY341495 (300 nm) when administered alone $(n=4)$ and antagonism of DCG-IV $(100 \mathrm{~nm})$ when coadministered $(n=4)$.

field, and locomotor activity was monitored for $20 \mathrm{~min}$ and scored offline. To analyze locomotor activity, the arena was divided with $6 \times 8$ grid lines, and the number of line crossings during each $5 \mathrm{~min}$ period of the test session was counted. A line crossing was recorded when the rat crossed a line with all four paws. Activity was further divided into outside and inside crossings in which an inside crossing was defined as crossing into any square other than those along the perimeter of the arena.

Elevated plus maze. The maze consisted of four $10 \times 70 \mathrm{~cm}$ arms, with a $35 \times 35 \mathrm{~cm}$ central platform elevated $85 \mathrm{~cm}$ above the floor. Two arms and the central platform were enclosed by opaque walls $30 \mathrm{~cm}$ high, whereas the other two arms were open. On each trial, a rat was placed on the central platform and then allowed to explore the maze for $5 \mathrm{~min}$. Before each trial, the platform and arms were cleaned with absolute ethanol. The rat's behavior was monitored via a video camera mounted above the maze, recorded, and scored offline. The following measures were scored: (1) time spent on the open arms, closed arms, and central secure area; (2) the number of entries into open and closed arms; and (3) the latency to enter an open arm and to enter a closed arm. An arm entry was scored when all four paws crossed the junction between the central area and an arm.

In all behavioral tests, the analyst was blind to the rat substrain, and unpaired Student's $t$ test was used to analyze differences between the two strains.

\section{Results}

Group II mGluRs in the TAP

As illustrated in Figure 1, we first confirmed that DCG-IV, a selective group II mGluR agonist, inhibited the fEPSP recorded in
CA1-SLM after TAP stimulation. The inhibition produced by DCG-IV was consistent, concentration dependent, and reversible (Fig. $1 A, B)(n=6)$. DCG-IV, applied for $30 \mathrm{~min}$ at 100,300 , and 1000 nM, resulted in inhibitions of $41 \pm 4,69 \pm$ 3 , and $76 \pm 3 \%$, respectively. Concentration-response curves were constructed and fitted with a logistics function. This gave a calculated $\mathrm{EC}_{50}$ of $80 \mathrm{~nm}$ and a maximum inhibition of $\sim 80 \%$ at $3000 \mathrm{nM}$ DCG-IV (Fig. 1C) $(n=4-10)$. These values are similar to those reported by Kew et al. (2001). Statistical analysis reveals a significant difference between sequential concentrations up to $1000 \mathrm{~nm}$ (one-way ANOVA with Bonferroni's post hoc test). To confirm that this inhibitory action was via group II receptors, we used the selective group II antagonist LY341495 (300 $\mathrm{nM}$ ), which itself was without significant effect on the fEPSP (Fig. $1 D)(n=4)$ but fully reversed the effects of $100 \mathrm{~nm}$ DCG-IV (Fig. $1 D)(n=4 ; p<0.001$, Student's paired $t$ test).

\section{Heterogeneity in group II actions in the TAP}

To differentiate between the roles of mGlu2 and mGlu3 receptors in the actions of DCG-IV, we used LY395756 as an mGlu2 agonist. Perplexingly, we found highly variable results. Thus, in some slices, 1-10 $\mu \mathrm{M}$ produced substantial inhibition (Fig. $2 \mathrm{~A}$ ), but, in others, these concentrations were almost without effect (Fig. 2 B). In such "insensitive" slices, 300 $\mu \mathrm{M}$ LY395756 was needed to induce a similar level of inhibition. The weak actions of LY395756 were not attributable to the absence of group II mGluRs because DCG-IV (100 nM) remained very effective (see below). When a scatter plot was constructed of the inhibitory effects of 1 and $10 \mu \mathrm{M}$ LY395756 on slices from the first 28 rats studied, it became obvious that the data fell into two significantly distinct groups $(p<0.001$, Student's unpaired $t$ test for each concentration) (Fig. 2C). Thus, 18 slices were "sensitive" to either 1 or $10 \mu \mathrm{M} \mathrm{LY395756} \mathrm{(56 \pm 2} \mathrm{and} 82 \pm 3 \%$ ), and 10 slices were essentially "insensitive" to these same two concentrations $(0 \pm 3$ and $9 \pm 3 \%)$. When concentration-response curves for the two populations were constructed and analyzed, $\mathrm{EC}_{50}$ values for LY395756 of 0.63 and $117 \mu \mathrm{M}$ were obtained (Fig. 2D) $(n=4-10)$.

For all subsequent experiments, LY395756 ( 1 or $10 \mu \mathrm{M}$ ) was applied to define preparations as either sensitive or insensitive and plotted in the figures as filled and open symbols, respectively. LY341495 (300 nM) fully reversed the effects of a near maximally effective concentration of LY395756 $(10 \mu \mathrm{M})$ in the sensitive preparations ( $p<0.001$, Student's paired $t$ test) (Fig. $2 E$ ), confirming that its actions were via group II mGluRs $(n=4)$. However, LY341495 had no significant effect on a submaximal concentration $(100 \mu \mathrm{M})$ of LY395756 in the insensitive preparations (Fig. $2 E$ ), suggesting that this effect was not mediated via activation of group II mGluRs $(n=4)$. 


\section{Origins of the heterogeneity}

One possible reason for the heterogeneity is that different afferent pathways were being stimulated in some experiments. Thus, for example, either the cortical pathways innervating CA1 polysynaptically via the dentate gyrus and CA3 or the SC pathway could have been stimulated inadvertently. Although from the shape and the latency of the fEPSPs the former seems unlikely, the majority of subsequent experiments were performed in modified CA1 slices (Fig. 3) (see Materials and Methods). Again, the data with LY395756 $(10 \mu \mathrm{M})$ from these modified slices fell into two clearly distinct groups (data not illustrated), with inhibitions of $74 \pm 4 \%(n=9)$ and $17 \pm 3 \%(n=12)$ ( $p<0.001$, Student's unpaired $t$ test). In an additional set of experiments to investigate the effects of LY395756 on the TAP and SC inputs into CA1, an extra stimulating electrode was placed in SC pathway, and the recording electrode was placed in the CA1 pyramidal cell layer (Fig. $3 A a$ ); the SC and TAP inputs were stimulated alternately. Again, the heterogeneity in the amount of inhibition induced by LY395756 was observed with the TAPevoked fEPSP ( $88 \pm 3 \%, n=5$; and $8 \pm$ $3 \%, n=3$ ), whereas the synaptic response to SC stimulation was consistently unaffected (Fig. $3 A b$ ). To further explore the possibility that the dichotomy in response arose as a result of stimulating different structures, in eight slices, two stimulating electrodes were placed on either side of the recording electrode in proximal and distal regions of the SLM (Fig. 3Ba). All eight pairs of evoked fEPSPs showed the same sensitivity to administration of LY395756; six pairs were sensitive and two were insensitive. A correlation coefficient of $r^{2}=0.91$ between the fEPSPs evoked from the two locations was obtained (Fig. $3 B b$ ). It should also be noted that, when multiple slices from the same rat were examined, they always showed the same degree of sensitivity to LY395756.

Horizontal slices have also been used to study the TAP input into CA1-SLM (Empson and Heinemann, 1995). Slices cut in this orientation were therefore studied with LY395756 (10 $\mu \mathrm{M})$, and again the same diverse results were found with inhibitions of $64 \pm 6 \%(n=4)$ and $11 \pm 8 \%(n=4)$ for the sensitive and insensitive slices, respectively (Fig. $3 C$ ).

The TAP arises from both lateral and medial areas of the entorhinal cortex. Input from these areas can be distinguished in the dentate gyrus by both sensitivity to group II mGluRs and using paired-pulse stimulation, which results in paired-pulse depression (PPD) in the medial and paired-pulse facilitation (PPF) in the lateral pathways (McNaughton, 1980; Macek et al., 1996; Kilbride et al., 1998). We therefore tested the possibility that pharmacological differences between sensitive and insensitive slices could be associated with differences in PPF or PPD. Paired-pulse (50 ms) stimulation, however, always induced PPF, with not significantly different ratios of $1.51 \pm 0.05$ and $1.63 \pm 0.07$ in both sensitive and insensitive slices, respectively (data not shown).
B
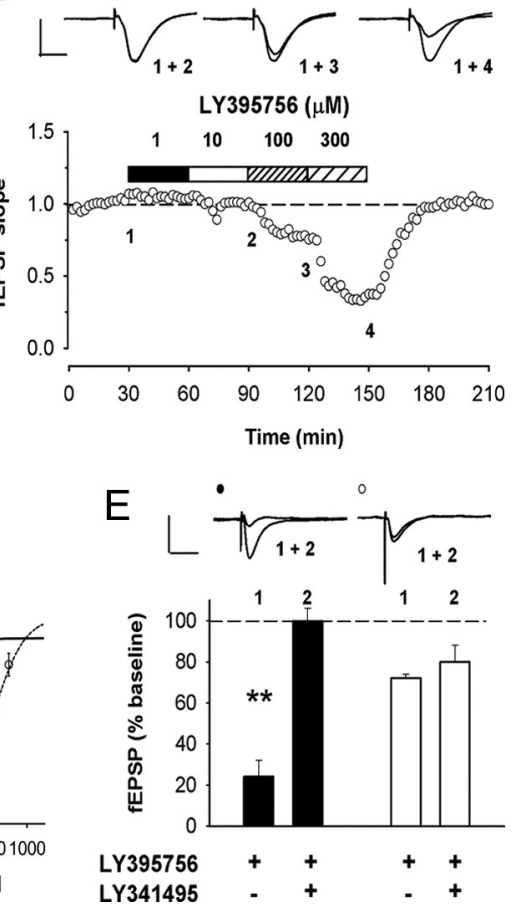

LY341495

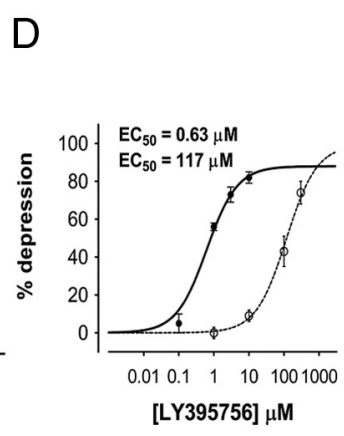

Figure 2. LY395756 has differential effects on synaptic transmission in the TAP-SLM pathway. $\boldsymbol{A}$, Single example in which LY395756 produced almost complete depression of the TAP-evoked fEPSP in CA1-SLM at $10 \mu \mathrm{M}$. After washout and recovery, ( induced by LY 395756 at two concentrations $(1 \mu \mathrm{M}, n=16: 10 \mu \mathrm{M}, n=16)$ in sensitive (filled circles) and insensitive (open circles) LY395756 (10 $\mu \mathrm{m} ; n=4$; filled bars). In contrast, in insensitive slices, it failed to reverse the small depressions induced by A

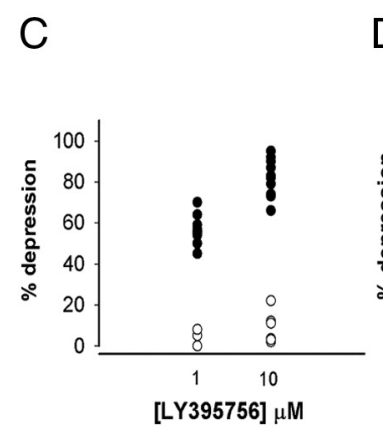

Furthermore, LY395756 (10 $\mu \mathrm{M})$ induced a significant increase in PPF to $1.94 \pm 0.14$ and $1.82 \pm 0.11$, respectively, in both types of slices $(p<0.05$, Student's paired $t$ test), consistent with a likely presynaptic mode of action in both pathways.

Rapid changes in neural development and receptor expression are occurring in neonatal rats. At $\sim 2$ weeks of age, there is an increase in mGlu2 mRNA and a decrease in mGlu3 mRNA (Catania et al., 1994), which could potentially explain the heterogeneity in sensitivity to the mGlu2 agonist LY39756. We investigated this by examining both younger and older animals, but again separation into sensitive and insensitive slices was observed in both groups. Thus, in rat pups of 7-10 d, LY395756 (10 $\mu \mathrm{M})$ reduced TAP-evoked fEPSPs by $73 \pm 9 \%(n=4)$ and by $8 \pm$ $3 \%(n=5)$ in sensitive and insensitive slices, respectively, and, similarly, in juveniles of $22-26 \mathrm{~d}$, both sensitive ( $61 \pm 7 \% ; n=7$ ) and insensitive $(2 \pm 2 \% ; n=7)$ preparations were again observed (data not illustrated).

\section{Differentiation of mGlu2 and mGlu3 pharmacology}

A possible explanation of the pharmacological heterogeneity is that LY395756 inhibits the synaptic response via mGlu2 receptors in the sensitive slices and that DCG-IV mainly inhibits the synaptic response in the insensitive slices via mGlu3 receptors. To test this hypothesis, we used the reported mGlu3 antagonist activity of LY395756 to challenge the action of DCG-IV in insensitive slices. A concentration of LY395756 (10 $\mu \mathrm{M})$ was initially 

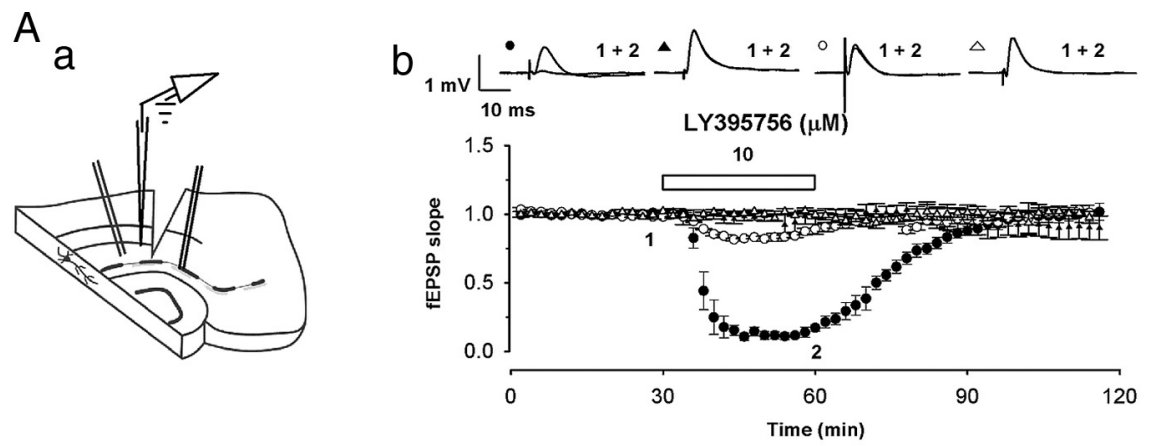

B

a

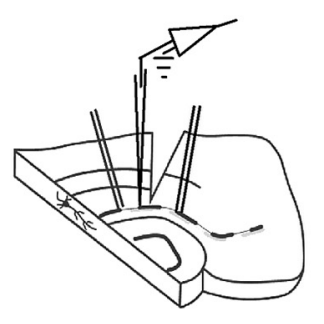

b

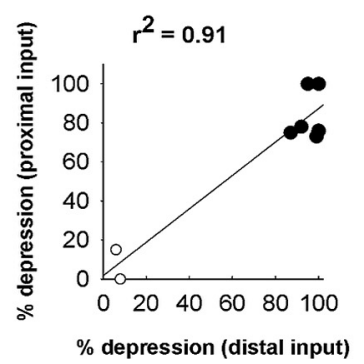

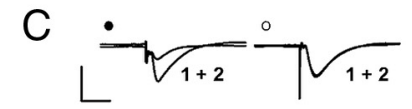

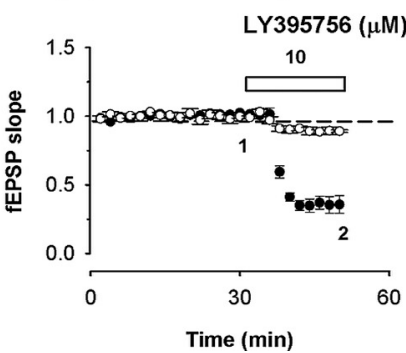

Figure 3. Pharmacological heterogeneity is maintained in the modified hippocampal slice preparation. $A$, Effects of LY395756 $(10 \mu \mathrm{M})$ recorded from the cell body layer in CA1-stratum pyramidale in modified slices $(\boldsymbol{A} \boldsymbol{a})$. Pooled data evoked by stimulation in the TAP-SLM (circles) and SC (triangles) from insensitive (open symbols; $n=3$ ) and sensitive (filled symbols; $n=5$ ) slices $(\boldsymbol{A} \boldsymbol{b})$. Statistical differences are indicated in Results. $\boldsymbol{B}$, Correlation between the depression of fEPSPs obtained by LY395756 (10 $\mu \mathrm{M})$ evoked after stimuli in the distal and proximal SLM (Ba) in insensitive (open circles; $n=2$ ) and sensitive (filled circles; $n=6$ ) slices, respectively $(\boldsymbol{B} \boldsymbol{b}) . \boldsymbol{C}$, In horizontal slices, the depression of the TAP-CA1 fEPSP with LY395756 (10 $\mu \mathrm{M})$ also falls into two populations of sensitive $(n=4)$ and insensitive $(n=4)$ slices.

selected that had little intrinsic inhibition on the insensitive slices (Fig. 2D) but which, according to studies using recombinant receptors, should be an effective mGlu3 antagonist (Dominguez et al., 2005). In insensitive slices, LY395756 partially antagonized the action of $100 \mathrm{~nm}$ DCG-IV by $\sim 60 \%(n=5)$ (Fig. $4 \mathrm{~A})$ in a fully reversible manner. Thus, the depression induced by DCG-IV was reduced from $51 \pm 9$ to $18 \pm 11 \%(p<0.05 ; n=5)$. In contrast, in sensitive slices, LY395756 produced a purely additive effect, increasing the inhibition from $57 \pm 5$ to $81 \pm 8 \%(n=5)$ (Fig. $4 B$ ), whereas in interleaved insensitive slices, as above, the inhibitory effect of DCG-IV was partially reversed. To better define the antagonist effect, various concentrations of LY395756 from 0.1 to $30 \mu \mathrm{M}$ were tested versus DCG-IV (100 nM) in insensitive slices $(n=4-11)$. A bell-shaped concentration-response curve was obtained (Fig. $4 C$ ), which suggested an $\mathrm{IC}_{50}$ of $\sim 0.66 \mu \mathrm{M}$. It should be noted that the biphasic nature of the concentrationresponse curve is likely attributable to the intrinsic inhibitory effect of LY395756 seen at high concentrations (Fig. 2D).

Analysis of the effects of DCG-IV in preparations sensitive and insensitive to LY395756 revealed only minor differences in their sensitivity to DCG-IV (for example, see Figure $4 B$ ). These results suggest that DCG-IV exerts its effect mainly via mGlu2 receptors in sensitive and via mGlu3 receptors in insensitive slices.

\section{Pharmacology of LY395756 in transgenic mice}

The above interpretation, however, relies on the reported pharmacology of LY395756 on heterologously expressed cloned human receptors (Dominguez et al., 2005). Therefore, to investigate its functional pharmacology on native group II mGluRs in rodents, we tested the compound on mice engineered so as not to

express either the mGlu2 or the mGlu3 receptor (Linden et al., 2005) (Fig. 5). In WT mice, LY395756 (1 and $10 \mu \mathrm{M})$ inhibited TAP-evoked fEPSPs in CA1-SLM by $41 \pm 4$ and $70 \pm 10 \%$, respectively $(n=$ 4). In contrast, in mGlu2 $\mathrm{KO}$ mice, LY395756 ( 1 and $10 \mu \mathrm{M})$ had no inhibitory action $(n=4)$ (Fig. $5 A)$. In mGlu3 KO mice, LY395756 had effects not dissimilar to those in wild-type mice, inhibiting fEPSPs by $35 \pm 6$ and $44 \pm 14 \%$, respectively $(n=5)$ (Fig. $5 C$ ).

When DCG-IV (300 nM) was superfused in mGlu2 $\mathrm{KO}$ mice, it produced an inhibition of $40 \pm 9 \%$, which was fully reversed by LY395756 (10 $\mu \mathrm{M} ; n=3)$ (Fig. $5 B$ ), whereas in mGlu3 $\mathrm{KO}$ mice, LY395756 $(10 \mu \mathrm{M})$ had a small additive effect increasing the DCG-IV inhibition from $47 \pm 6$ to $53 \pm 10 \%$ (Fig. $5 D)(n=4)$.

These data are consistent with the actions of LY395756 as a functional mGlu2 agonist and mGlu3 antagonist on native rodent receptors. The similarity of the mice and rat data supports our assertion of the different roles of mGlu2 and mGlu3 receptors in the sensitive and insensitive rats.

\section{Rat strain differences account for the diverse effects of LY395756}

The dichotomy in these data suggested that there may be genetic variation within the University of Bristol rat breeding colony used for these studies. This colony consisted of Wistar rats purchased originally from Charles River (Crl:Wi) and more recently from B\&K Universal Ltd (B\&K:Wi). During the course of our electrophysiological study (2006-2009), the ratio of sensitive to insensitive rats reduced, which potentially correlated with the introduction of the B\&K rats into the breeding colony. Another possible explanation was that there had been some change in management, handling, environment, etc., that resulted in different phenotypes. We investigated both these possibilities by purchasing rats from different sources.

Wistar rats were therefore bought from the above two United Kingdom suppliers. The fEPSPs recorded in CA1-SLM after TAP stimulation of Crl:Wi rats were reduced by $84 \pm 6 \%$ by $10 \mu \mathrm{M}$ LY395756 (Fig. 6A) $(n=9)$, whereas, in rats from B\&K:Wi, fEPSPs were unaffected $(-1 \pm 7 \% ; n=9)$ (Fig. 6A). Furthermore, as in sensitive slices, LY395756 produced a small additional depression when added in the presence of DCG-IV in Crl:Wi rats, whereas, as in insensitive slices, LY395756 antagonized the response to DCG-IV in B\&K:Wi rats. These results show that strain differences do indeed underlie the differences in pharmacology.

Subsequently, we determined that the insensitive B\&K:Wi rats were derived from Wistar lineage from the Hannover Institute, so-called Han strains (Fig. 6B), whereas the sensitive Crl:Wi strain was more directly descended from the Wistar Institute. Most Wistar rats commercially available in the United Kingdom belong to the Han substrain. We therefore tested three other lines of Han strain rats with LY395756 (10 $\mu \mathrm{M})$ and found they had a mixed population of sensitive and insensitive rats (Fig. 6A). Thus, of 10 Crl.Han:Wi rats, six were sensitive $(87 \pm 5 \%$ inhibi- 

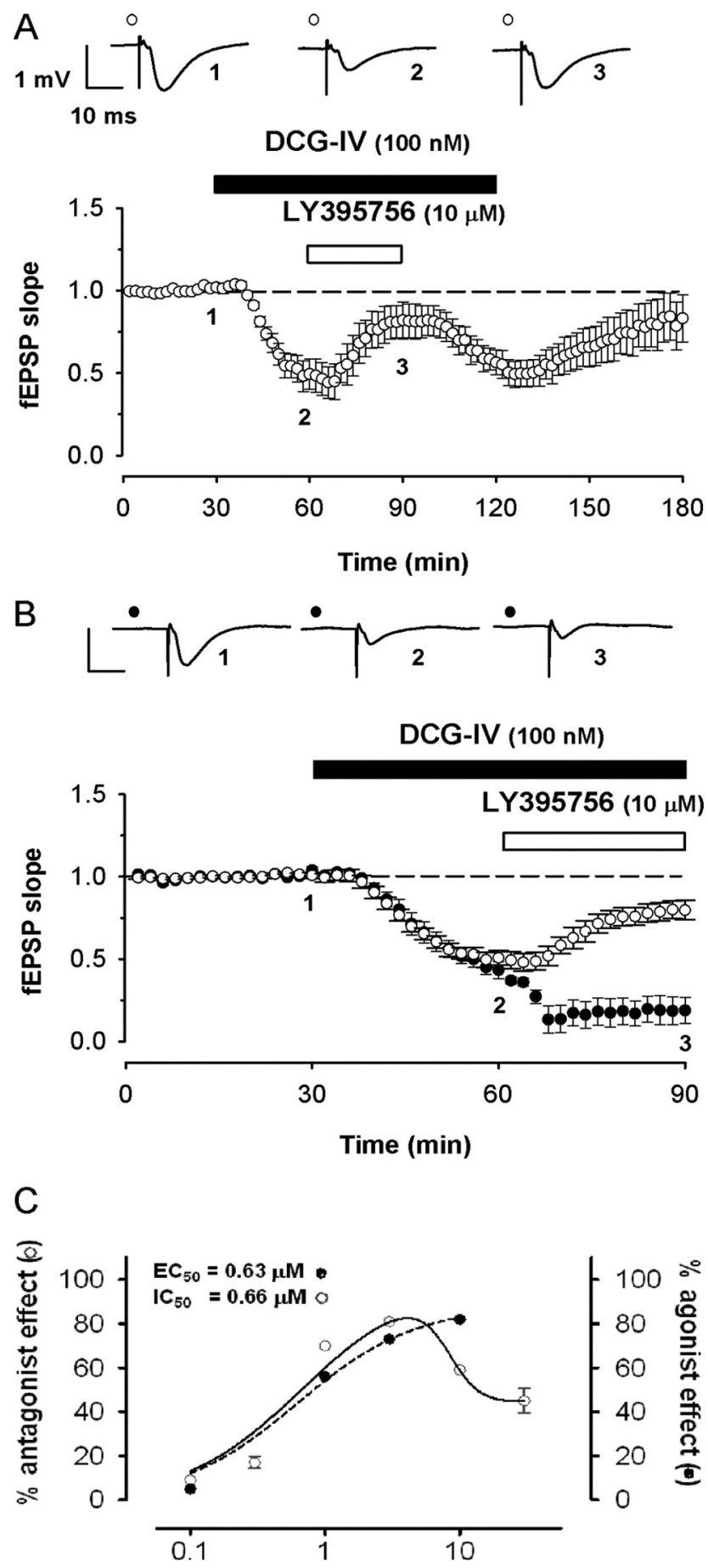

\section{[LY395756] $\mu \mathrm{M}$}

Figure 4. LY395756 antagonizes the actions of DCG-IV only in insensitive slices. A, Pooled data from five insensitive slices showing the antagonist action of LY395756 (10 $\mu \mathrm{M})$ versus depression induced by DCG-IV (100 nm). B, Pooled data showing the effect of LY395756 during the application of DCG-IV (100 nM) in insensitive (open circles; $n=11$ ) and sensitive (filled circles; $n=5$ ) slices. Note how it acts as an antagonist and an agonist, respectively. Note also the lack of significant difference between the effects of DCG-IV in the two types of slices. $C$, Concentration-response curve for the agonist effect of L $L 395756$ in sensitive slices (filled circle; dotted line) overlaps with the bell-shaped curve of the antagonist effect of LY395756 in insensitive slices (open circles; solid line). Each data point is the mean \pm SEM of 4-10 experiments. tion) and four insensitive ( $7 \pm 5 \%)$. Of seven Harlan Hsd:Wi rats, one was sensitive $(95 \%)$ and six were insensitive $(5 \pm 3 \%)$. Of seven Harlan Rcc:Wi rats, four were sensitive $(81 \pm 2 \%)$ and three insensitive $(-5 \pm 8 \%)$. We also tested a non-Wistar rat strain from B\&K Universal Ltd.; all nine Sprague Dawley rats were of the sensitive phenotype ( $90 \pm 4 \%)$ (Fig. $6 A)$. These findings rule out a determining influence of management and/or environmental differences in defining phenotype, because rats from the same suppliers, and even within the same litter, expressed different sensitivities to LY395756.

\section{Confirmation of differences in group II mGluR expression} levels in two substrains

To further understand the differences in pharmacology between these rat strains, we also performed Western blotting using antibodies selective for mGlu2 and mGlu3. Initially, we confirmed the selectivity of the two antibodies using hippocampal tissue from the transgenic mice (Fig. 7A). Next we used these two antibodies on samples prepared from modified CA1 slices defined as sensitive and insensitive electrophysiologically, which were Crl:Wi and B\&K:Wi rats, respectively. This showed that hippocampal tissue from insensitive $\mathrm{B} \& \mathrm{~K}$ :Wi rats had reduced expression of the mGlu2 receptor protein relative to that of the sensitive Crl:Wi strain (Fig. 7B). Interestingly this appears likely to be a global difference because whole parasagittal slices and the cortical, striatal, and cerebellar regions from the adjacent slices showed the same pattern of mGlu2 receptor expression (Fig. $7 B, C)$. When the same samples were probed with the mGluR3 antibody, no difference between the strains was detected in its expression (Fig. $7 B, D$ ).

\section{Behavioral assays}

Observations of rats in their home cages and during handling suggested some differences in behavior between the sensitive and insensitive strains. It was therefore decided to look for a straindependent behavioral phenotype.

We initially examined the behavior of the two rat strains in an open-field assay. First, we observed that the Crl:Wi rats showed greater exploratory behavior, especially in the inner areas of the arena, than the B\&K:Wi rats. Second, we found that a group II mGluR agonist, LY379268 (3 mg/kg, i.p.) (data not shown), reduced the exploratory behavior in the Crl:Wi rats but was ineffective in the B\&K:Wi rats. These studies suggested that there is a strain-dependent behavioral phenotype and that this may involve a difference in the expression of group II mGluRs. However, these initial studies were conducted on animals purchased from different sources. This could introduce behavioral variables attributable to the different environmental factors associated with the two sources.

To minimize the effect of such environmental differences, $\mathrm{B} \& \mathrm{~K}: \mathrm{Wi}$ and Crl:Wi rats were bred in-house, randomly housed, matched carefully, and treated identically. Analysis of exploratory and anxiety-related behaviors in a full open-field assay of these age- and rearing-matched controls revealed no overall differences in locomotor activity (Fig. $8 \mathrm{~A}$; for total activity, see Table 1, top). The Crl:Wi rats, however, spent relatively more time in the interior of the arena (Fig. $8 \mathrm{~B}$ ) and made more rears while in these inner areas (Table 1, bottom) than did B\&K:Wi rats. This phenotype has been interpreted as anxiety like (Cryan and Holmes, 2005). The two strains were also tested in the elevated plus maze, which relies on rodents aversion to open space and height to assess anxiety-related behaviors (File, 2001). The B\&K:Wi rats spent less time in the open arms (Fig. $8 C$ ), made less entries into 


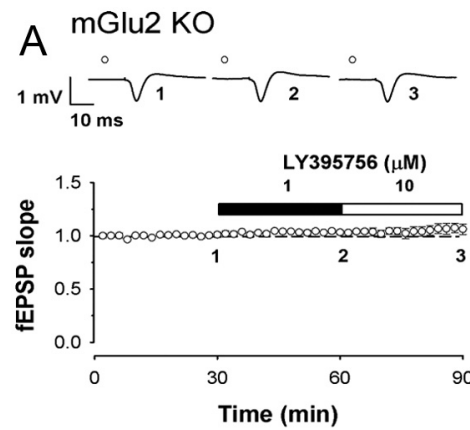

B
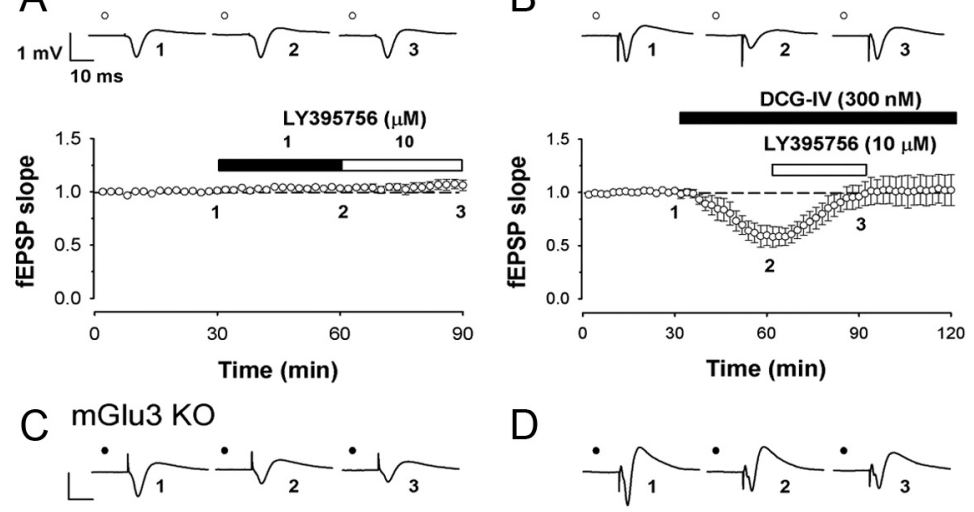

D
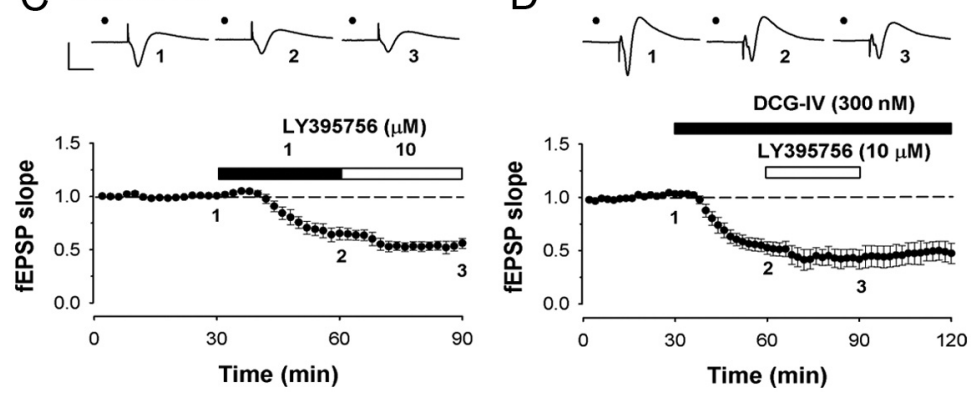

Figure 5. Actions of LY395756 in group II mGluR knock-out mice. $A-D$, Effect of LY395756 (1-10 $\mu \mathrm{M})$ in mGlu2 KO $(A, B)$ and mGlu3 KO $(\boldsymbol{C}, \boldsymbol{D})$ mice (pooled data, $n=3-5)$. LY395756 (1-10 $\mu \mathrm{M})$ is without effectin mGlu2 KO mice $(\boldsymbol{A})$ but depresses the fEPSP response in mGlu3 K0 mice (C). LY395756 (10 $\mu \mathrm{m})$ also antagonizes the action of DCG-IV (300 nM) in mGlu2 KO (B) but not in mGlu3 KO (D) mice.

A

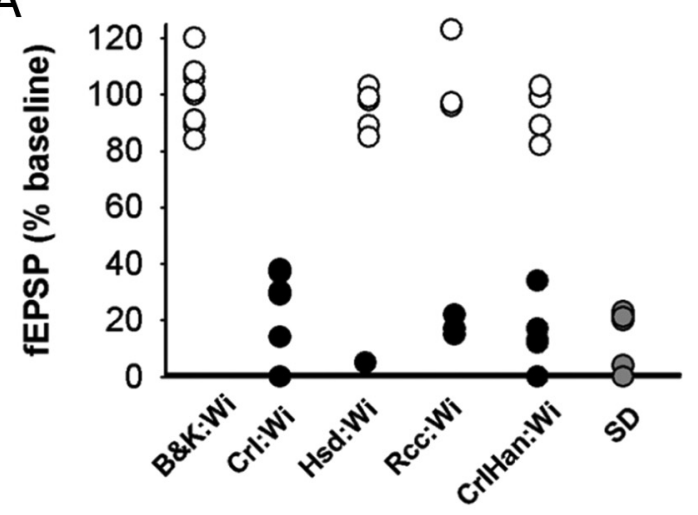

$\mathrm{B}$

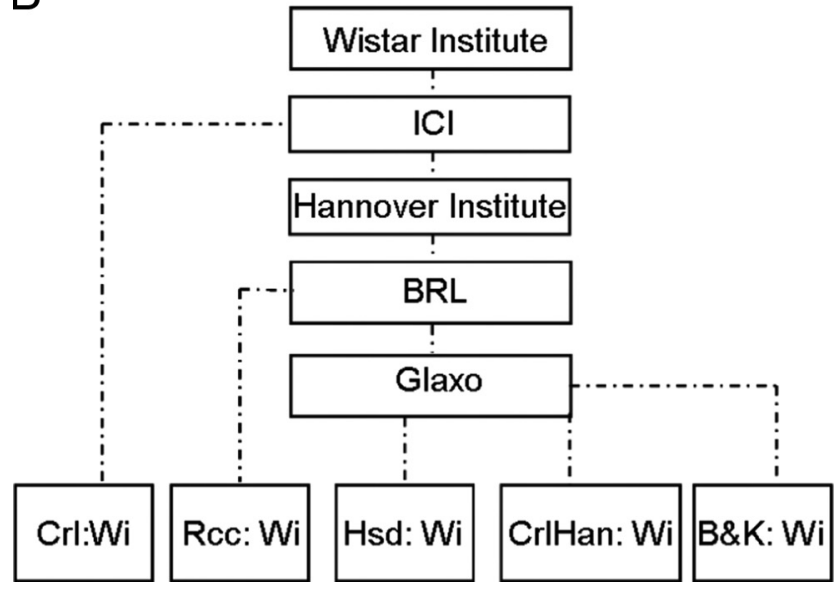

Figure 6. Effects of $L Y 395756$ on substrains of Wistar rats. A, Scatter grams showing the effect of LY395756 on TAP-evoked fEPSPs in five different substrains of Wistar rats and one strain of Sprague Dawley (SD) rats. Open circles indicate an effect similar to insensitive preparations and filled circles to sensitive ones. Gray circles represent the data from Sprague Dawley rats. $\boldsymbol{B}$, Simplified scheme of the relationship and apparent derivation of the different substrains of Wistar rats. the open arms (Fig. 8D), and took longer to venture into an open arm (Fig. 8E) compared with the Crl:Wi rats (for details, see Table 1, bottom). Interestingly, the time spent in the closed arms was the same for both strains, but the B\&K:Wi rats spent more time in the central secure area (Table 1, bottom).

In both the open-field and elevate plus maze assays, the rats have a conflict between seeking safe areas and exploring novel locations (File, 2001; Cryan and Holmes, 2005). The difference between the two strains suggests therefore that the insensitive $\mathrm{B} \& \mathrm{~K}: \mathrm{Wi}$ rats have a more anxiety-like profile.

To confirm that the expression of mGlu2 receptors was still missing in these 12 -week-old rats, we tested the sensitivity of hippocampal slices from rats used in the behavioral assays. As can be seen in Figure $8 F$, slices from $\mathrm{B} \& \mathrm{~K}: \mathrm{Wi}$ rats remained insensitive to $10 \mu \mathrm{M}$ LY395756 $(0 \pm 7 \%$ inhibition $)$, whereas a robust sensitivity to this mGlu2 agonist was found in the Crl:Wi rats $(60 \pm 13 \%)$.

\section{Discussion}

The present study has shown that LY395756 is a valuable tool for understanding the roles of native mGlu2 and mGlu3 receptors. We have confirmed that mGlu2 receptors regulate synaptic transmission in the TAP input to CA1-SLM but have made the surprising observation that mGlu3 receptors can also fulfill this role. Furthermore, we have discovered a rat strain with low expression of mGlu2 receptors, which also displays an anxiety-like phenotype in two animal models of anxiety.

\section{LY395756 as a tool for differentiating mGlu2 and mGlu3 receptors}

There is a lack of compounds for distinguishing between the two group II receptors. $\mathrm{N}$-acetylaspartylglutamate (NAAG) and $\beta$-NAAG have been reported as selective mGlu3 ligands (Wroblewska et al., 1997), but there are concerns with the use of NAAG (Fricker et al., 2009). There are selective positive allosteric modulators of mGlu2, but these require agonist activation of the receptor to show effects (Johnson et al., 2003; Galici et al., 2005). Clearly, additional subtype-selective compounds are required.

Orthosteric compounds have certain advantages. LY395756 is such an orthosteric agent (compound 13) (Dominguez et al., 2005). It displaces ${ }^{3} \mathrm{H}$-LY341495 binding equi-effectively from heterologously expressed human mGlu2 and mGlu3 receptors, but in forskolin-stimulated cAMP assays, it is an agonist at mGlu2 $\left(\mathrm{EC}_{50}\right.$ of $0.40 \mu \mathrm{M}$ ) and an antagonist at mGlu3 receptors [ $\left[\mathrm{IC}_{50}\right.$ of $2.94 \mu \mathrm{M}$ vs $30 \mu \mathrm{M}(1 S, 3 R)$-1-amino-1,3-cyclopentanedicarboxylic acid]. In the present studies, LY395756 was an agonist in sensitive slices with an $\mathrm{EC}_{50}$ of $\sim 0.63 \mu \mathrm{M}$ and an antagonist in insensitive slices with an $\mathrm{IC}_{50}$ of $\sim 0.66 \mu \mathrm{M}$ (vs $100 \mathrm{~nm}$ DCG-IV). The replication of these observations in mGlu3 and mGlu2 $\mathrm{KO}$ mice, respectively, supports the original description (Dominguez et al., 2005) of this compound as a mixed mGlu2 agonist/mGlu3 antagonist and importantly extends the observations to native rodent receptors. This makes LY395756 a very useful tool for distinguishing roles of native mGlu2 and mGlu3 receptors. 
Experiments on the University of Bristol rat colony

DCG-IV being an effective and reliable inhibitor of the TAP input into CA1-SLM, an effect reversed by $300 \mathrm{nM}$ LY341495, it was concluded that this was a group II mGluR effect, most likely mediated by mGlu2 receptors, according to immunohistochemical (Petralia et al., 1996; Shigemoto et al., 1997; Tamaru et al., 2001) and electrophysiological (Kew et al., 2002) data. It was therefore surprising that, in some of our first experiments with the mGlu2 receptor agonist, LY395756, there was no or little inhibition up to $10 \mu \mathrm{M}$, despite the fact that DCG-IV at $100 \mathrm{~nm}$ was effective in the same slice. It quickly became apparent that the data fell into two distinct populations, a sensitive and an insensitive group.

There were a number of plausible explanations for the data. For example, small variations in positioning of the stimulating electrode could have preferentially activated the SC pathway or the trisynaptic pathway via dentate gyrus and CA3 neurons to CA1, resulting in a different mGlu2 agonist sensitivity relative to the direct TAP input. These were excluded by cutting through the SC pathway and removing the majority of dentate gyrus and CA3 (Empson and Heinemann, 1995) This, however, did not exclude the possibility of a differential effect of LY395756 on the medial versus the lateral entorhinal layer III inputs via the TAP into SLM, as observed for medial and lateral perforant path inputs into dentate gyrus (Macek et al., 1996; Kilbride et al., 1998; Kew et al., 2001). Different stimulating electrode positions in a single slice, multiple slices from the same rat, and different slice orientations, however, all gave a similar magnitude of response to LY395756. These results are all consistent with pharmacological sensitivity differences between individual rats.

This interpretation was confirmed by taking sensitive and insensitive slices and analyzing them for mGlu2 and mGlu3 receptor expression by Western blot using antibodies that we demonstrated were selective for these proteins in mice expressing only mGlu2 or mGlu3 receptors. The immunochemistry results clearly show a huge differential expression of the mGlu2 receptor between the two types of electrophysiologically characterized slices.

\section{Strain differences explain the heterogeneity}

The original Wistar Institute rat strain has been re-derived at various institutes and commercial establishments (Fig. $7 B$ ). In Europe, the Hannover Institute was the source of many, but not all, subsequently developed lines; these are termed Han Wistars. The University of Bristol Animal Services Unit bred Wistar rats
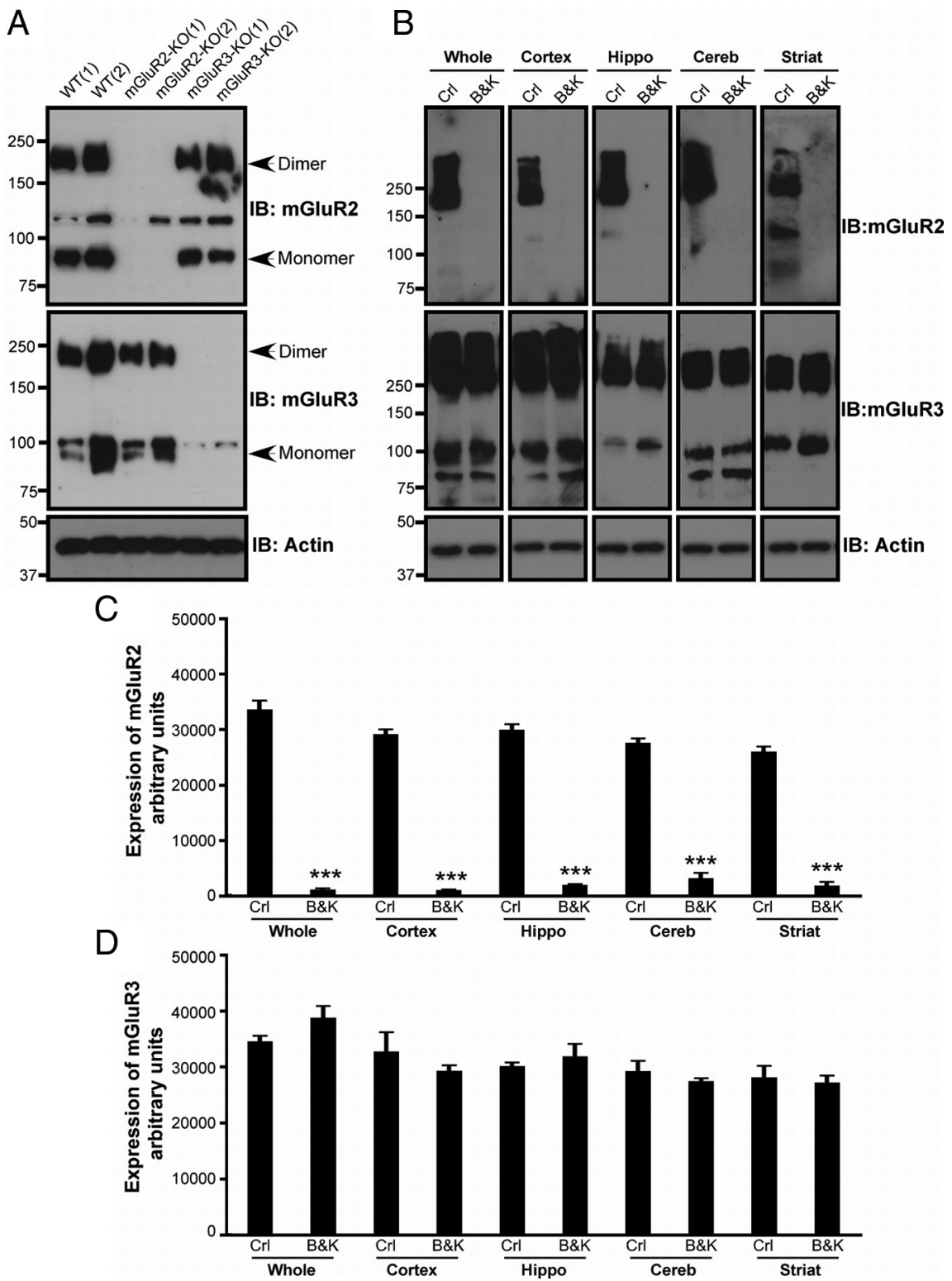

Figure 7. Expression of $m G l u 2$ and $m G l u 3$ in tissues from knock-out mice and different substrains of Wistar rats. A, Specificity of $\mathrm{mGlu2}$ and $\mathrm{mGlu3}$ receptor antibodies determined by Western blots using tissue from adult hippocampal slices from two WT, two $\mathrm{mGlu2} \mathrm{K0}$, and two mGlu3 $\mathrm{KO}$ mice. These antibodies were used at $1 \mu \mathrm{g} / \mathrm{ml}$ concentration and are selective for $\mathrm{mGlu2}$ and mGlu3 proteins. The same blots were probed with anti-actin antibody $(0.2 \mu \mathrm{g} / \mathrm{ml})$ to ensure equal loading. $\boldsymbol{B}$, Western blots performed using the same antibodies on a parasagittal slice (Whole) and the cortical (Cortex), hippocampal (Hippo), cerebellar (Cereb), and striatal (Striat) regions of adjacent slices from postnatal day $14 \mathrm{Crl}$ :Wi sensitive and B\&K:Wi insensitive rats. The sensitivity to LY395756 was verified in hippocampal slices from the same rats. $\boldsymbol{C}, \boldsymbol{D}$, Histogram of densitometric analysis of the protein expression of mGlu2 $(\boldsymbol{C})$ and $\mathrm{mGlu3}(\boldsymbol{D})$ receptors, respectively, as shown in $\boldsymbol{B}$ using $\mathrm{NIH} \mathrm{ImageJ.} \mathrm{IB,} \mathrm{Immunoblot.}{ }^{* *} p<$ 0.001 compared with control (Student's $t$ test).

that were either Han Wistars from B\&K Universal Ltd. (B\&K:Wi) or non-Han Wistars from Charles River (Crl:Wi), which we show here are the sources of insensitive and sensitive rats, respectively. Other commercial sources of Han Wistars had both insensitive and sensitive rats. Although a full analysis of all Wistar strains is beyond the scope here, it appears that the insensitive phenotype has arisen in rat strains from the Hannover Institute. Rat strains showing divergent pharmacological and behavioral phenotypes are well established, mostly developed by selective breeding for phenotype (Overstreet, 2002). For example, there are Wistar lines bred for alcohol preference (McBride and Li, 1998), attention deficits (Sagvolden, 2000), and increased anxiety, possibly as a 
A

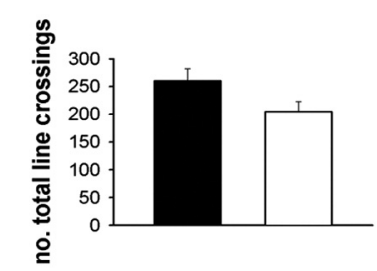

C

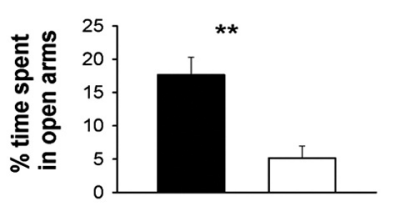

E

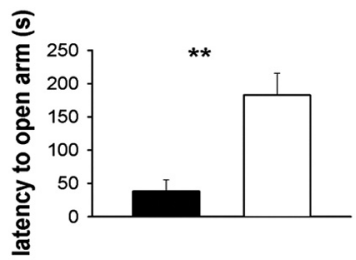

B

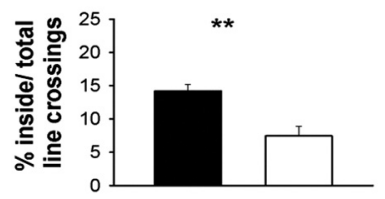

D
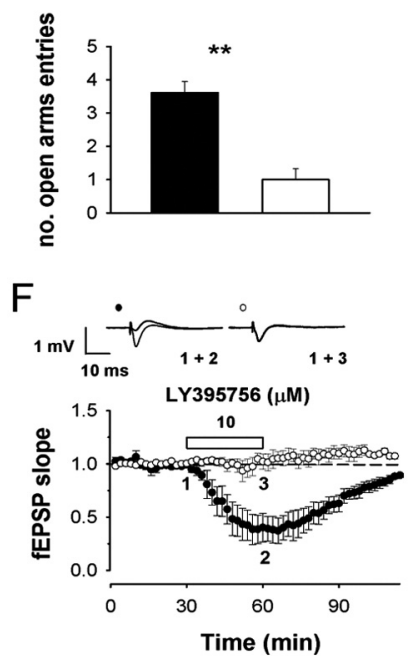

Figure 8. Behavioral studies in Crl:Wi and B\&K:Wi rats. $\boldsymbol{A}, \boldsymbol{B}$, Open-field assay; $\boldsymbol{C}-\boldsymbol{E}$, elevated plus maze assay. $A$, Histogram showing total locomotor activity over $20 \mathrm{~min}$ in the open field expressed as the number of line crossings in 5 min epochs made by Crl:Wi (filled bar) and B\&K:Wi (open bar) rats. $\boldsymbol{B}$, Histograms showing greater tendency of Crl:Wi rats (filled bar) to explore the inner areas of the open-field arena. Line crossings in the inside area of the open field are normalized by expressing as a percentage of total number of line crossings in the 5 min test. C, Histograms showing that Crl:Wi (filled bar) rats spend more time in the open arms of the elevated plus maze expressed as percentage of total 5 min compared with B\&K:Wi rats (open bar). $\boldsymbol{D}$, Histograms showing that (rl:Wi rats (filled bar) make more entries into the open arm from the central area of the elevated plus maze than B\&K:Wi rats (open bar). $\boldsymbol{E}$, Histograms showing that the Crl:Wi rats (filled bar) enter the open arms of the elevated plus maze more quickly than B\&K:Wi rats (open bar), expressed as the latency to the first open arm entry. $\boldsymbol{F}$, Actions of LY395756 (10 $\mu \mathrm{m})$ on synaptic transmission in the TAP-SLM pathway of Crl:Wi (filled circles) and B\&K:Wi (open circles) rats used previously for the above behavioral assays. The sample traces are taken from one of the experiments as indicated on the graph.

result of overexpression of vasopressin (Landgraf and Wigger, 2003). In contrast, the marked phenotypic differences in mGlu2 receptor expression described here have arisen serendipitously.

\section{Implications of the observed strain differences}

An important cautionary note resulting from these studies is that the use of a single strain of rat can lead to major errors of interpretation. For example, it would be impossible to determine any role for mGlu2 receptors in $\mathrm{B} \& \mathrm{~K}: \mathrm{Wi}$ rats, and their use could exaggerate the role of $\mathrm{mGlu} 3$ receptors.

Mixed mGlu2/3 receptor agonists such as LY354740 and LY379268 have been used in behavioral assays and in animal models of disease to investigate the role of group II receptors. They were first shown to cross the blood-brain barrier (Bond et al., 1997) and then to have neuroprotective (Bond et al., 1998), anxiolytic (Helton et al., 1998), and anti-convulsant (Monn et al., 1999) properties. The neuroprotective (Bruno et al., 2001), anxiolytic (Walker et al., 2002; Schoepp et al., 2003), and anticonvulsant (Smolders et al., 2004) effects have been confirmed and extended to inflammatory and neuropathic pain (Simmons et

Table 1. Behavioral data

\begin{tabular}{llll}
\hline & Crl:Wi & B\&K:Wi & Statistical analysis \\
\hline Open field & $n=13$ & $n=13$ & \\
$\quad$ Number of line crossings in & $260.3 \pm 22.1$ & $204.4 \pm 18.5$ & $t_{(24)}=1.94, p>0.05$ \\
$\quad 20$ min & & & \\
\% outside/total line crossings & $85.8 \pm 1.0$ & $92.5 \pm 1.4$ & $t_{(24)}=3.92, p<0.005$ \\
\% inside/total line crossings & $14.2 \pm 1.0$ & $7.5 \pm 1.4$ & $t_{(24)}=3.92, p<0.005$ \\
Total number of rears & $95.5 \pm 6.3$ & $68.8 \pm 5.5$ & $t_{(24)}=3.27, p<0.01$ \\
\% outside/total of rears & $92.8 \pm 1.1$ & $97.3 \pm 0.6$ & $t_{(24)}=3.58, p<0.01$ \\
\% inside/total of rears & $7.2 \pm 1.1$ & $2.7 \pm 0.7$ & $t_{(24)}=3.58, p<0.01$ \\
Elevated plus maze & $n=13$ & $n=14$ & \\
\% time spent in closed arms & $45.9 \pm 2.7$ & $48.3 \pm 2.7$ & $t_{(25)}=0.61, p>0.1$ \\
\% time spent in centre & $36.4 \pm 2.8$ & $46.5 \pm 2.3$ & $t_{(25)}=2.83, p<0.01$ \\
\% time spent in open arms & $17.7 \pm 2.6$ & $5.2 \pm 1.8$ & $t_{(25)}=4.00, p<0.001$ \\
Total number of entries & $9.7 \pm 0.5$ & $8.3 \pm 0.3$ & $t_{(25)}=2.24, p<0.05$ \\
Number of closed arm entries & $6.1 \pm 0.3$ & $7.3 \pm 0.3$ & $t_{(25)}=2.62, p<0.05$ \\
Number of open arm entries & $3.6 \pm 0.3$ & $1.0 \pm 0.3$ & $t_{(25)}=5.58, p<0.001$ \\
Latency to first closed arm & $24.5 \pm 5.3$ & $21.7 \pm 6.4$ & $t_{(25)}=0.33, p>0.1$ \\
$\quad$ entry (s) & & & \\
Latency to first open arm & $38.1 \pm 17.3$ & $182.5 \pm 33.0$ & $t_{(25)}=3.79, p<0.005$ \\
$\quad$ entry (s) & & & \\
\hline
\end{tabular}

Data from open field (top) and elevated plus maze (bottom) behavioral assays on matched 9- to 11-week-old rats from sensitive (Crl:Wi) and insensitive (B\&K:Wi) strains. Values are given as the mean \pm SEM and $t$ (degrees of freedom) and $p$ values from Student's $t$ test.

al., 2002; Jones et al., 2005) and to animal models of schizophrenia (Moghaddam and Adams, 1998; Cartmell et al., 2000a,b). In human clinical trials, peptide prodrugs of LY354740 and related compounds have shown efficacy in anxiety states (Grillon et al., 2003; Dunayevich et al., 2008) and in schizophrenia (Patil et al., 2007).

In the absence of compounds discriminating effectively between mGlu2 and mGlu3 receptors, it is unclear which of these two receptor subtypes is responsible for these diverse effects. Results from transgenic mice point to mGlu2 receptors mediating the effects of the mixed agonist in models of schizophrenia (Fell et al., 2008; Woolley et al., 2008), whereas human tissue studies favor a role for mGlu3 receptors in psychiatric disease (Corti et al., 2007a; Harrison et al., 2008). The mGlu2 receptors also appear to mediate the analgesic effects of mixed agonists (Chiechio et al., 2009), whereas mGlu3 receptors mediate their neuroprotective effects (Corti et al., 2007b), and their anxiolytic activity appears to be mediated by both group II receptors (Linden et al., 2005). However, the initial behavioral observation that the insensitive B\&K:Wi strain shows a more anxiety-like profile suggests that the lack of $m$ Glu2 receptors may be one of the factors leading to an anxious phenotype and may suggest that mGlu 2 receptors mediate at least some of the anxiolytic actions of mixed mGlu2/3 agonists reported in the clinic (Grillon et al., 2003; Dunayevich et al., 2008), although mGlu2 $\mathrm{KO}$ mice are not reported to have an anxious phenotype (Linden et al., 2005). A more thorough ethographic survey of these two strains is needed before the full phenotype related to the $\mathrm{mGlu} 2$ receptor deficit can be elucidated.

Because most animal models of neurological and psychiatric conditions have been developed in the rat, a rat substrain not expressing mGlu2 receptors could have many advantages for preclinical research. Equally, the same substrain expressing primarily mGlu3 receptors should be useful in determining the roles of these receptors using standard pharmacological tools, which in normal rats have the complication of also activating mGlu2 receptors. In particular, it will be useful for differentiating the roles of the two group II mGlu receptors in neuroprotection studies. Interestingly, in the present study, the similarity in the effects of DCG-IV on the sensitive and insensitive rat strains, as an inhibitor of the TAP input into CA1-SLM, imply that mGlu3 receptors 
are able to fulfill the function of the missing mGlu2 receptor. It remains to be studied whether there is some upregulation on the TAP terminals or whether mGlu3 receptors in other places, for example in astrocytes, compensate for the missing neuronal mGlu2 receptors.

In conclusion, we believe the present results contribute to our understanding of the roles of group II metabotropic receptors. The elucidation of a subtype-selective compound and of a strain of rat not expressing mGlu2 receptors that has an anxiety-like phenotype will allow the therapeutic potential of the two constituent mGlu receptors to be studied more precisely.

\section{References}

Anderson WW, Collingridge GL (2007) Capabilities of the WinLTP data acquisition program extending beyond basic LTP experimental functions. J Neurosci Methods 162:346-356.

Bond A, Monn JA, Lodge D (1997) A novel orally active group 2 metabotropic glutamate receptor agonist: LY354740. Neuroreport 8:1463-1466.

Bond A, O’Neill MJ, Hicks CA, Monn JA, Lodge D (1998) Neuroprotective effects of a systemically active group II metabotropic glutamate receptor agonist LY354740 in a gerbil model of global ischaemia. Neuroreport 9:1191-1193.

Bruno V, Battaglia G, Copani A, D’Onofrio M, Di Iorio P, De Blasi A, Melchiorri D, Flor PJ, Nicoletti F (2001) Metabotropic glutamate receptor subtypes as targets for neuroprotective drugs. J Cereb Blood Flow Metab 21:1013-1033.

Capogna M (2004) Distinct properties of presynaptic group II and III metabotropic glutamate receptor-mediated inhibition of perforant pathway-CA1 EPSCs. Eur J Neurosci 19:2847-2858.

Cartmell J, Schoepp DD (2000) Regulation of neurotransmitter release by metabotropic glutamate receptors. J Neurochem 75:889-907.

Cartmell J, Monn JA, Schoepp DD (2000a) The mGlu(2/3) receptor agonist LY379268 selectively blocks amphetamine ambulations and rearing. Eur J Pharmacol 400:221-224.

Cartmell J, Monn JA, Schoepp DD (2000b) Attenuation of specific PCPevoked behaviors by the potent $m$ Glu2/3 receptor agonist, LY379268 and comparison with the atypical antipsychotic, clozapine. Psychopharmacology (Berl) 148:423-429.

Catania MV, De Socarraz H, Penney JB, Young AB (1994) Metabotropic glutamate receptor heterogeneity in rat brain. Mol Pharmacol 45:626-636.

Ceolin L, Bortolotto ZA, Collingridge GL, Lodge D (2008) Differentiation of perforant path inputs into CA1 by an mGluR2 agonist, LY395756. Neuropharmacology 55:591.

Chiechio S, Zammataro M, Morales ME, Busceti CL, Drago F, Gereau RW 4th, Copani A, Nicoletti F (2009) Epigenetic modulation of mGlu2 receptors by histone deacetylase inhibitors in the treatment of inflammatory pain. Mol Pharmacol 75:1014-1020.

Colbert CM, Levy WB (1992) Electrophysiological and pharmacological characterization of perforant path synapses in CA1: mediation by glutamate receptors. J Neurophysiol 68:1-8.

Corti C, Crepaldi L, Mion S, Roth AL, Xuereb JH, Ferraguti F (2007a) Altered dimerization of metabotropic glutamate receptor 3 in schizophrenia. Biol Psychiatry 62:747-755.

Corti C, Battaglia G, Molinaro G, Riozzi B, Pittaluga A, Corsi M, Mugnaini M, Nicoletti F, Bruno V (2007b) The use of knock-out mice unravels distinct roles for mGlu2 and mGlu3 metabotropic glutamate receptors in mechanisms of neurodegeneration/neuroprotection. J Neurosci 27:8297-8308.

Cryan JF, Holmes A (2005) The ascent of mouse: advances in modelling human depression and anxiety. Nat Rev Drug Discov 4:775-790.

Dominguez C, Prieto L, Valli MJ, Massey SM, Bures M, Wright RA, Johnson BG, Andis SL, Kingston A, Schoepp DD, Monn JA (2005) Methyl substitution of 2-aminobicyclo[3.1.0] hexane 2,6-dicarboxylate (LY354740) determines functional activity at metabotropic glutamate receptors: identification of a subtype selective mGlu2 receptor agonist. J Med Chem 48:3605-3612.

Dunayevich E, Erickson J, Levine L, Landbloom R, Schoepp DD, Tollefson GD (2008) Efficacy and tolerability of an mGlu2/3 agonist in the treatment of generalized anxiety disorder. Neuropsychopharmacology 33:1603-1610.

Empson RM, Heinemann U (1995) The perforant path projection to hip- pocampal area CA1 in the rat hippocampal-entorhinal cortex combined slice. J Physiol 484:707-720.

Fell MJ, Svensson KA, Johnson BG, Schoepp DD (2008) Evidence for the role of metabotropic glutamate ( $\mathrm{mGlu}) 2$ not $\mathrm{mGlu} 3$ receptors in the preclinical antipsychotic pharmacology of the mGlu2/3 receptor agonist (-)(1R,4S,5S,6S)-4-amino-2-sulfonylbicyclo[3.1.0] hexane-4,6-dicarboxylic acid (LY404039). J Pharmacol Exp Ther 326:209-217.

File SE (2001) Factors controlling measures of anxiety and responses to novelty in the mouse. Behav Brain Res 125:151-157.

Fricker AC, Mok MH, de la Flor R, Shah AJ, Woolley M, Dawson LA, Kew JN (2009) Effects of N-acetylaspartylglutamate (NAAG) at group II mGluRs and NMDAR. Neuropharmacology 56:1060-1067.

Galici R, Echemendia NG, Rodriguez AL, Conn PJ (2005) A selective allosteric potentiator of metabotropic glutamate (mGlu) 2 receptors has effects similar to an orthosteric mGlu2/3 receptor agonist in mouse models predictive of antipsychotic activity. J Pharmacol Exp Ther 315:1181-1187.

Giocomo LM, Hasselmo ME (2006) Difference in time course of modulation of synaptic transmission by group II versus group III metabotropic glutamate receptors in region CAl of the hippocampus. Hippocampus 16:1004-1016.

Grillon C, Cordova J, Levine LR, Morgan CA 3rd (2003) Anxiolytic effects of a novel group II metabotropic glutamate receptor agonist (LY354740) in the fear-potentiated startle paradigm in humans. Psychopharmacology (Berl) 168:446-454.

Harrison PJ, Lyon L, Sartorius LJ, Burnet PW, Lane TA (2008) The group II metabotropic glutamate receptor 3 (mGluR3, mGlu3, GRM3): expression, function and involvement in schizophrenia. J Psychopharmacol 22:308-322.

Hayashi Y, Momiyama A, Takahashi T, Ohishi H, Ogawa-Meguro R, Shigemoto R, Mizuno N, Nakanishi S (1993) Role of a metabotropic glutamate receptor in synaptic modulation in the accessory olfactory bulb. Nature 366:687-690.

Helton DR, Tizzano JP, Monn JA, Schoepp DD, Kallman MJ (1998) Anxiolytic and side-effect profile of LY354740: a potent, highly selective, orally active agonist for group II metabotropic glutamate receptors. J Pharmacol Exp Ther 284:651-660

Johnson MP, Baez M, Jagdmann GE Jr, Britton TC, Large TH, Callagaro DO, Tizzano JP, Monn JA, Schoepp DD (2003) Discovery of allosteric potentiators for the metabotropic glutamate 2 receptor: synthesis and subtype selectivity of N-(4-(2-methoxyphenoxy)phenyl)-N-(2,2,2- trifluoroethylsulfonyl)pyrid-3-ylmethylamine. J Med Chem 46:3189-3192.

Jones CK, Eberle EL, Peters SC, Monn JA, Shannon HE (2005) Analgesic effects of the selective group II (mGlu2/3) metabotropic glutamate receptor agonists LY379268 and LY389795 in persistent and inflammatory pain models after acute and repeated dosing. Neuropharmacology 49 [Suppl 1]:206-218

Kew JN, Ducarre JM, Pflimlin MC, Mutel V, Kemp JA (2001) Activitydependent presynaptic autoinhibition by group II metabotropic glutamate receptors at the perforant path inputs to the dentate gyrus and CA1. Neuropharmacology 40:20-27.

Kew JN, Pflimlin MC, Kemp JA, Mutel V (2002) Differential regulation of synaptic transmission by mGlu2 and mGlu3 at the perforant path inputs to the dentate gyrus and CA1 revealed in mGlu2 $-/-$ mice. Neuropharmacology 43:215-221.

Kilbride J, Huang LQ, Rowan MJ, Anwyl R (1998) Presynaptic inhibitory action of the group II metabotropic glutamate receptor agonists, LY354740 and DCG-IV. Eur J Pharmacol 356:149-157.

Kingston AE, Ornstein PL, Wright RA, Johnson BG, Mayne NG, Burnett JP, Belagaje R, Wu S, Schoepp DD (1998) LY341495 is a nanomolar potent and selective antagonist of group II metabotropic glutamate receptors. Neuropharmacology 37:1-12.

Landgraf R, Wigger A (2003) Born to be anxious: neuroendocrine and genetic correlates of trait anxiety in HAB rats. Stress 6:111-119.

Linden AM, Shannon H, Baez M, Yu JL, Koester A, Schoepp DD (2005) Anxiolytic-like activity of the mGLU2/3 receptor agonist LY354740 in the elevated plus maze test is disrupted in metabotropic glutamate receptor 2 and 3 knock-out mice. Psychopharmacology (Berl) 179:284-291.

Macek TA, Winder DG, Gereau RW 4th, Ladd CO, Conn PJ (1996) Differential involvement of group II and group III mGluRs as autoreceptors at lateral and medial perforant path synapses. J Neurophysiol 76:3798-3806.

McBride WJ, Li TK (1998) Animal models of alcoholism: neurobiology 
of high alcohol-drinking behavior in rodents. Crit Rev Neurobiol 12:339-369.

McNaughton BL (1980) Evidence for two physiologically distinct perforant pathways to the fascia dentata. Brain Res 199:1-19.

Moghaddam B, Adams BW (1998) Reversal of phencyclidine effects by a group II metabotropic glutamate receptor agonist in rats. Science 281:1349-1352.

Monn JA, Valli MJ, Massey SM, Wright RA, SalhoffCR, Johnson BG, Howe T, Alt CA, Rhodes GA, Robey RL, Griffey KR, Tizzano JP, Kallman MJ, Helton DR, Schoepp DD (1997) Design, synthesis, and pharmacological characterization of (+)-2-aminobicyclo[3.1.0] hexane-2,6-dicarboxylic acid (LY354740): a potent, selective, and orally active group 2 metabotropic glutamate receptor agonist possessing anticonvulsant and anxiolytic properties. J Med Chem 40:528-537.

Monn JA, Valli MJ, Massey SM, Hansen MM, Kress TJ, Wepsiec JP, Harkness AR, Grutsch JL Jr, Wright RA, Johnson BG, Andis SL, Kingston A, Tomlinson R, Lewis R, Griffey KR, Tizzano JP, Schoepp DD (1999) Synthesis, pharmacological characterization, and molecular modeling of heterobicyclic amino acids related to (+)-2-aminobicyclo[3.1.0] hexane-2,6-dicarboxylic acid (LY354740): identification of two new potent, selective, and systemically active agonists for group II metabotropic glutamate receptors. J Med Chem 42:1027-1040.

Niswender CM, Conn PJ (2010) Metabotropic glutamate receptors: physiology, pharmacology, and disease. Annu Rev Pharmacol Toxicol 50:295-322.

Overstreet DH (2002) Behavioral characteristics of rat lines selected for differential hypothermic responses to cholinergic or serotonergic agonists. Behav Genet 32:335-348.

Patil ST, Zhang L, Martenyi F, Lowe SL, Jackson KA, Andreev BV, Avedisova AS, Bardenstein LM, Gurovich IY, Morozova MA, Mosolov SN, Neznanov NG, Reznik AM, Smulevich AB, Tochilov VA, Johnson BG, Monn JA, Schoepp DD (2007) Activation of mGlu2/3 receptors as a new approach to treat schizophrenia: a randomized Phase 2 clinical trial. Nat Med 13:1102-1107.

Petralia RS, Wang YX, Niedzielski AS, Wenthold RJ (1996) The metabotropic glutamate receptors, mGluR2 and mGluR3, show unique postsynaptic, presynaptic and glial localizations. Neuroscience 71:949-976.

Price CJ, Karayannis T, Pal BZ, Capogna M (2005) Group II and III mGluRs-mediated presynaptic inhibition of EPSCs recorded from hippocampal interneurons of CA1 stratum lacunosum moleculare. Neuropharmacology 49 [Suppl 1]:45-56.
Sagvolden T (2000) Behavioral validation of the spontaneously hypertensive rat (SHR) as an animal model of attention-deficit/hyperactivity disorder (AD/HD). Neurosci Biobehav Rev 24:31-39.

Schoepp DD, Jane DE, Monn JA (1999) Pharmacological agents acting at subtypes of metabotropic glutamate receptors. Neuropharmacology 38:1431-1476.

Schoepp DD, Wright RA, Levine LR, Gaydos B, Potter WZ (2003) LY354740, an mGlu2/3 receptor agonist as a novel approach to treat anxiety/stress. Stress 6:189-197.

Shigemoto R, Kinoshita A, Wada E, Nomura S, Ohishi H, Takada M, Flor PJ, Neki A, Abe T, Nakanishi S, Mizuno N (1997) Differential presynaptic localization of metabotropic glutamate receptor subtypes in the rat hippocampus. J Neurosci 17:7503-7522.

Simmons RM, Webster AA, Kalra AB, Iyengar S (2002) Group II mGluR receptor agonists are effective in persistent and neuropathic pain models in rats. Pharmacol Biochem Behav 73:419-427.

Smolders I, Lindekens H, Clinckers R, Meurs A, O’Neill MJ, Lodge D, Ebinger G, Michotte Y (2004) In vivo modulation of extracellular hippocampal glutamate and GABA levels and limbic seizures by group I and II metabotropic glutamate receptor ligands. J Neurochem 88:1068-1077.

Steward O, Scoville SA (1976) Cells of origin of entorhinal cortical afferents to the hippocampus and fascia dentata of the rat. J Comp Neurol 169:347-370.

Tamaru Y, Nomura S, Mizuno N, Shigemoto R (2001) Distribution of metabotropic glutamate receptor mGluR3 in the mouse CNS: differential location relative to pre- and postsynaptic sites. Neuroscience 106:481-503.

Walker DL, Rattiner LM, Davis M (2002) Group II metabotropic glutamate receptors within the amygdala regulate fear as assessed with potentiated startle in rats. Behav Neurosci 116:1075-1083.

Witter MP, Amaral DG (2004) Studies on the structure of the cerebral cortex. II. Continuation of the study of the ammonic system. In: The rat nervous system, Ed 3 (Paxinos G, ed), pp 637-703. San Diego: Elsevier Academic.

Woolley ML, Pemberton DJ, Bate S, Corti C, Jones DN (2008) The mGlu2 but not the mGlu3 receptor mediates the actions of the mGluR2/3 agonist, LY379268, in mouse models predictive of antipsychotic activity. Psychopharmacology (Berl) 196:431-440.

Wroblewska B, Wroblewski JT, Pshenichkin S, Surin A, Sullivan SE, Neale JH (1997) N-acetylaspartylglutamate selectively activates mGluR3 receptors in transfected cells. J Neurochem 69:174-181. 